Letras, Lima 48 (82-83): 107-119, 1976.

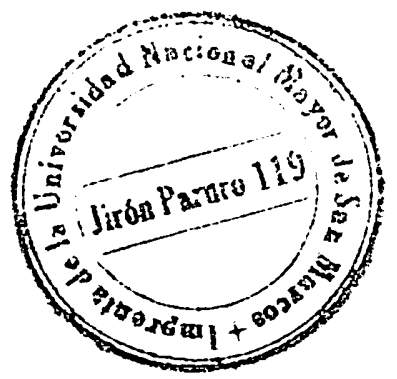

\title{
Matalaché: las varias formas de la esclavitud
}

\author{
ANTONO CORNEJO POLAR
}

A primera vista Matalaché (1) es una novela muy sencilla, elemental casi, que proyecta todos sus recursos estilísticos y representativos hacia la expresión de un mensaje unívoco que pretende confundirse en grado extremo, sustantivamente, con la motivación creadora de su autor. En este sentido Matalaché es una obra concebida bajo el modelo de la "novela de tesis". En efecto, en su célebre respuesta a Ramiro de Maeztu, López Albújar dejó en claro que su novela era una afirmación de la incontenible fuerza del amor: "por encima del distanciamiento del título, de la fortuna y del color de la piel -decía don Enrique- está la atracción de los sexos, el apoder irresistible del genio de la especie" (2). Interesaba en especial al creador de Matalaché condenar la falsa jerarquía de las razas. Es frente a ésta, contextualizada en lo personal dentro del campo de las relaciones eróticas entre negros y blancos y en lo social dentro del sistema esclavista, que Enrique López Albújar exclamaba con entonación inconfundiblemente romántica: "el amor salva toda barrera" (3). La historia de los amores de María Luz y el mulato esclavo José Manuel (Matalaché) está obviamente destinada a postular esta tesis. De hecho, cuando la novela se escribe (1928), la esclavitud es cosa del pasado nacional, pero la discriminación racial mantiene, sin duda, todo su rigor.

Matalaché no es, sin embargo, una novela tan escueta como podría desprenderse de una primera visión. Su relectura -relectura

(1) Enrique López Albújar. Matalaché; novela retaguardista. Piura, El Tiempo, 1928. Citamos la ed. de Juan Mejía Baca \& P. L. Villanueva. Lima, [1955].

(2) La carta se publica como prólogo a la ed. de Matalaché que utilizamos, p. 10.

(3) Op. cit., p. 11. 
que proponemos en estas páginas- descubre niveles de complejidad y riqueza que la crítica ha pasado por alto (4).

\section{La credibilidad de lo insólito}

El argumento de Matalaché es básicamente lineal, aunque contiene eventuales retracciones evocativas, y deviene íntegramente de un narrador omnisciente que enfoca un universo ya pasado, el de los años finales de la dominación española en el Perú (el texto menciona la fecha de 1816, p. 23). El narrador va desenvolviendo un solo hilo argumental (5) cuyo ordenamiento y ritmo buscan, una suerte de dosificación que confiera credibilidad al insólito suceso central. La pasión de María Luz se observa como un proceso que constantemente se intensifica hasta culminar en la entrega de la bellísima hija de don Juan Francisco de los Ríos, "estremecida y agónica" (p. 151), a su esclavo Matalaché. La excepcionalidad de este suceso, abiertamente en pugna con el orden social evocado en la novela, exige al narrador un cuidadoso empleo de sus recursos. Se trata de obtener un grado satisfactorio de verosimilitud; más concretamente, de hacer verosímil lo insólito.

Queda insinuado que a este objetivo tiende la presentación dosificada del suceso; en especial, el paulatino y gradual apasionamiento de María Luz. Del simple reconocerse como objeto del deseo masculino, primero de los marinos de la nave que la conduce de Lima a Piura ("le parecía que esos hombres la desnudaban con los ojos y que, después de recrearse en los misterios de su cuerpo, con sádica delectación, le disparaban unos dardos cañdentes a las entrañas", p. 37), y luego de los esclavos de su padre. "eran unas miradas estuprantes, que levantaban las ropas mujeriles y Geariciaban las carnes con viscosidad de caracol", p. 47) (6), María Luz pasa a descubrir en sí misma la capacidad de placer, cuando al amparo de la voluptuosa siesta siente "como unas ondas sutiles que nacían primero en el vientre y después se le metían en el corazón, sublevándole, para en seguida, de

(4) En Cuadernos del Consejo Nacional de la Universidad Peruana (Lima, diciembre de 1972, No. 11) acaba de aparecer un artículo de Raúl Estuardo Cornejo, "Las fuentes de Matalaché", donde se anuncia el descubrimiento de un manuscrito (se trata del inventario de los bienes de quien fuera propietario de La Tina) que, según el articulista, "dio a la imaginación del autor el punto de partida para construir la trama de su novela" - aspecto que, a nuestros fines, carece de relieve. Conoceremos también la próxima aparición de un libro de Tomás G. Escajadillo sobre la narrativa de López Albújar, libro que incluye un extenso capítulo acerca de Matalaché.

(5) Aludimos a los amores de María Luz y José Manuel. Las referencias al problema de la esclavitud $\mathrm{y}$ a las tensiones previas a la Independencia del Perú no constituyen categorías argumentales.

(6) La familia reconoce que María Luz "es una tentación". Esta es la razón por la que se le envía de Lima a Piura (p. 30). 
un salto, agarrársele a los exúberos pechos, haciéndole desfallecer" (pp. 50-51), de suerte que cuando finalmente la protagonista imagina, decide y realiza su entrega a José Manuel, es una nueva secuencia claramente escondida, el lector puede recomponer con facilidad las graduales instancias del devenir de una pasión ejemplar (7).

De otra parte, y como procedimiento que refuerza al anterior, el narrador interpola fragmentos descriptivos que separan los distintos momentos del discurrir psicológico de María Luz, o al menos, los de mayor relieve. Así se le otorga en el nivel de la lectura, que es sin duda donde se juega la suerte de la verosimilitud, la apariencia de un ritmo menos vivo del que -en verdad vertiginoso- tiene en el tiempo del relato. La pausa descriptiva cumple mejor su función en la medida en que su ley estilística es la de la reiteración. El discurso se paraliza mientras grandes series enumerativas saturan por adición un solo significado: rosales, jazmines, diamelas, chavelas, alhelíes, etc., descritos minuciosamente, no hacen más que demostrar con su lozanía el poder de María Luz "sobre las almas [y] también sobre las cosas" (p. 94).

No deja de tener importancia, dentro de estas mismas consideraciones, la preocupación del narrador por circunstanciar el suceso central en orden a facilitar la realización de ciertos actos y su inmediata explicación en el ánimo del lector. Hay evidente interés en explicar por qué María Luz no vive en la casona piurana sino en La Tina, con la vecindad de los esclavos; por qué visita la fábrica guiada por Matalaché, justo cuando su padre está ausente; cómo puede conocer a través de Rita, la única esclava que José Manuel excepcionalmente respeta, el valor moral, el lado íntimo de quien, para el resto, no es más que "un garañón capaz de apechugarse con todas las criadas de la ciudad en una noche"r (p. 18); cómo el esclavo, de pronto habilísimo artesano, es capaz de comunicar con sus obras una pasión que jamás podría romper el silencio impuesto por su condición, etc.

El orden primario del universo

Pero la verosimilitud del relato no proviene sólo de los recursos empleados en la representación. Se solventa en un nivel tal vez menos evidente pero sin duda más activo, que implica la actualización de una concepción del universo y ofrece una opción significativa de primera importancia en la composición total de la novela: la formulación de un orden causal, orden que el narrador enfatiza constantemente Se trata de diseñar la ligazón causa-efecto de los actos y sucesos que el texto representa y de conferirles, por este camino, un trasfondo explicativo de naturaleza fuertemente racional. En la línea medular del relato hay un visible esfuerzo por encontrar y poner en claro la razón de la pasión, en este caso su engranaje causal, que parece de-

(7) No es el caso de Matalaché cuya pasión por María Luz es inmediata. 
rivar del canon que se acepta para la totalidad del universo. Es un orden cuyo ancestro positivista no pasa desapercibido (8).

Destacan en el repertorio de causas que despliega el autor, tanto por la frecuencia con que aparecen cuanto por la amplitud explicativa que se les concede, algunas que implican una concepción del universo humano como producto de condicionamientos naturales o biológicos. Así, por ejemplo, Piura es vista casi como un "don del sol”. Todo lo que allí existe está condicionado por su irrestricto imperio:

$\mathrm{Y}$ es que en la tierra piurana todo lleva el sello del sol (...) Y no sólo está en las bestias y en las cosas sino también en el hombre, $y$ en todo lo que el hombre piensa y hace (p. 35, subrayado nuestro).

La mujer piurana es hechura del sol — señala el narrador- y María Luz no sería lo que es ni haría lo que hace sin gozar y sufrir su impacto:

Es él el sol quien primero habla a su sexo; quien la prepara y la incita a conocer el misterio de la fecundidad; quien la espolvorea en la mente el polvo mágico de los ensueños y en la urna sexual, los primeros ardores de la femineidad; quien le despierta tempranamente la imaginación a las falaces sugestiones de la especie ( p. 35).

Son estas "sugestiones de la especie" (9), que garantizan con legislación inexorable la supervivencia del género humano, el otro gran polo causal del relato. Los individüos āman guiados por esa fuerza que los incluye en una tarea suprapersonal: en este sentido, el amor es la

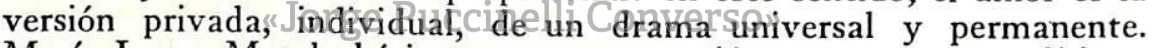
María Luz y Matalaché intuyen que su pasión, aunque personalísima, viene dictada por un poder que definitivamente es superior a ellos. El lector así lo comprende y no puede dejar de pensar en las ya citadas palabras de López Albújar: se trata, en efecto, del "poder irresistible del genio de la especie".

Esa suerte de "determinismo geográfico" y las sostenidas reflexiones sobre el imperio de la especie se ensamblan en el relato con la

(8) En la literatura peruana no es insólito advertir la mezcla de romanticismo y positivismo. Esta es una de las características del realismo en el Perú, como puede apreciarse ejemplarmente en Aves sin nido. Por lo demás, es evidente la dificultad de ubicar la obra de López Albújar en el proceso de la literatura nacional. El subtítulo de Matalaché, "novela retaguardista", que debe entenderse en una primera instancia como un signo desafiante contra la generación inmediatamente posterior, tiene, sin embargo, mucha mayor significación. Este es un tema que deberá desarrollar con esmero la historia literaria.

(9)) Obviamente el término "falaces" no armoniza en modo alguno con el sentido que en toda la novela se confiere a las "sugestiones de la especie". 
creencia en la diferencialidad (no jerarquía) de los atributos de las razas y en la vigencia de éstas sobre la vida de los individuos. Las virtualidades propias de cada raza se constituyen como campos delimitados en cuyo interior la persona actualiza modelos indesligables de una raíz biológica. Según se verá luego, la excepcionalidad de Matalaché deriva en buena parte del impacto que recibe de dos razas distintas, cada una de ellas con sus caracteres identificatorios y peculiares. Cuando el mulato José Manuel termina la confección del frontal encomendado por María Luz, el narrador puede encontrar en esa obra lo que corresponde a las razas que confluyen en el artesano. En resumen:

En su híbrido cerebro había prevalecido la célula más civilizada. El simbólico azul de su sangre ibérica había comunicado mayor fuerza a su inspiración que el rojo de su sangre africana (p. 124).

En el universo de la novela, medio físico, especie y raza forman un sistema conceptual que explica los niveles básicos de la existencia humana. Son causas profundas que el narrador tiene siempre en un primer plano como signos de la concepción que anima y organiza el relato en su integridad. En este sentido, todo acontecer, hasta la intimidad de la pasión erótica, resuelve su identidad diferencial en un patrón común, universal, que la razón humana puede asimilar y comprender.

La perversión del universo social

El lector de Matalaché descubre muy pronto que esa racionalidad del universo se quiebra, y muy gravemente, en el nivel de los hechos sociales. En determinados momentos podría parecer que la sociedad en su conjunto implica una constante violación del orden primario del universo. La vida social tergiversa insistentemente la auténtica causalidad para reemplazarla, en diversos grados, por un sistema sólido pero irracional: el de los prejuicios. La tenaz oposición entre estos dos órdenes, cuyos ejes pudieran sintetizarse en la doble pareja: naturaleza y razón/ sociedad e irracionalidad (prejuicios), genera toda la dinámica interior del relato.

Un prejuicio preocupa intensamente al narrador: el de la jerarquía de las razas. A partir de él se acepta consensualmente la subhumanidad del negro y se instituye la legitimidad del sistema esclavista. El texto contiene innumerables referencias al respecto. Desde las páginas iniciales de la novela, en el diálogo entre don Juan Francisco y don Baltazar Rejón de Mesones, y pese a que luego el primero será definido como un amo humanitario ("don Juan Francisco trataba a sus esclavos humanamente", p. 61), se plantea como cosa aceptada la siniestra situación social del negro esclavo. El dueño de La Tina, que contagiado por un vago liberalismo piensa que "hay que 
levantar un poco [la] condición de hombres" de los esclavos (p. 27), no puede ocultar, sin embargo, su radical apego al sistema imperante: "si necesito una buena acémila o un magnífico esclavo, los compro", dice (p. 21). Don Baltazar es más tajante: "esclavos y animales son una misma cosa" (id.). De ello tienen plena conciencia los propios esclavos. Matalaché se encarga de explicitarlo: "un esclavo y un perro son la misma cosa para el amo", señala hacia el final de la novela (p. 108).

No es casual, entonces, el insistente uso de términos sacados de la zoología para caracterizar a los personajes negros. Naturalmente los amos blancos los emplean de manera regular ("garañón, "oveja", "tigrillo"), pero también - paradójicamente- los propios personajes negros para hablar de sus semejantes ("borreguita", "lagarto", "toro matrero"). Se trata en este último caso de una manifestación de la abatida conciencia de los negros, secularmente víctimas de la opresión más terrible, conciencia que sólo parece recuperar su dignidad en eventuales afirmaciones de humanidad ("una no es animal", dice Rita, p. 37) o en las lucubraciones político-libertarias de José Manuel, cuyo paradigma humano es, sin embargo, el de sus opresores: "así son los blancos caballeros, y así debemos ser nosotros", afirma ante otros esclavos (p. 77) (10).

Curiosamente las referencias zoológicas no quedan sólo en boca de los personajes. También aparecen, con frecuencia todavía mayor y cargadas de inocultables acentos peyorativos, en el discurso del narrador. Para el narrador, Matalaché tiene mirar "ofídico" (pp. 38, 74); Casilda luce una sonrisa "caprina" (p. 43); otro esclavo queda descrito por su "chimpancesco mentón" (p. 43); mientras que Rita y Casilda - para acabar Ioscejemplos con el Smás significativo- resultan no ser más juye "pobres mamíferos domésticos" (p. 185). Este ambiguo y contradictorio aspecto del lenguaje del narrador, que tiene otras manifestaciones paralelas, igualmente desconcertantes, pone en duda la base misma del sentido de la tesis de la novela, lo que equivaldría a la frustración de su explícito mensaje igualitario. Este punto, de importancia capital, será materia de reflexión posterior. Ahora basta mencionarlo como una imprevisible muestra, insólitamente traspuesta del universo representado al plano de la actitud narrativa, del poder de ese pervertido orden social, amparado nada más que en prejuicios, que de alguna manera logra contaminar incluso a quienes, abierta y constantemente, lo condenan.

Pero la novela no sólo muestra el prejuicio social contra los negros. Capta también una vasta gama de actitudes irracionales que tergiversan el sentido de la vida humana e impiden su realización

(10) Este juicio de José Manuel está en referencia directa con su relación con el mundo blanco y con su concepto acerca de la "esclavitud" de todos quienes, blancos o negros, están sojuzgados por España. Ambos temas serán tratados más adelante. 
natural, plena. Amor y sexualidad sufren una permanente y dolorosa distorsión. La forzada abstinencia de los negros ("sus miradas reflejaban todo el ardor de la continencia forzada, el ansia de deseos mal contenidos, el grito sofocado de la virilidad comprimida", p. 47) o su actividad sexual controlada por los amos, que sólo ven en ella una manera de incrementar el número de sus siervos y, por consiguiente, de su riqueza, son parte, tal vez la más visible, por feroz, de ese continuo sometimiento de la sensibilidad y sentimiento humanos frente a lo irracional y antinatural. El "poder irresistible del genio de la especie" parece abdicar ante la ceguera y maldad del hombre. Y no se trata solamente de una derivación del estatuto esclavista: también los blancos, los poderosos amos que parecen condicionar el mundo a su voluntad, están sometidos a una similar distorsión. Los artificiales matrimonios por conveniencia, los adulterios, el tabú sexual y las inhibiciones permanentes son los rasgos predominantes de su vida afectiva. Contra ellos se rebela María Luz.

Aunque sin el énfasis con que son representados los anteriores, pero con igual o similar acento condenatorio, la novela hace desfilar otra serie de prejuicios que enturbian la existencia del hombre en sociedad: la necesidad de aparentar riqueza; la educación formal; la religiosidad falsificada, en algunos casos convertida en simple recurso para vivir placenteramente, como el narrador lo advierte a través de la figura del cura Sota (11), son otras tantas maneras, entre muchas más, de pervertir el orden natural del mundo y de falsear los valores del hombre.

\section{Biblioteca La marginalidad de los rebeldes}

López Albújar consideraba que con su heroína María Luz había logrado crear un "tipo de contraposición en un ambiente de prejuicios sociales" (12). Ciertamente es así, y ello produce un conjunto de repercusiones importantes en la composición del relato. Es claro que la oposición se plantea no entre individualidades encontradas sino entre una de éstas, caracterizada con especial esmero, y el sistema de hábitos y valores ("ambiente") de un grupo social -grupo cuyos miembros aparecen, por lo demás, apenas esbozados en el texto (13). Es el caso de María Luz, según lo advierte López Albújar, pero es igualmente, si bien se mira, el de José Manuel. Ambos personajes se oponen incisivamente a sus respectivos grupos sociales: son conscientes de su marginalidad, derivada de su carácter excepcional, dis-

(11) El narrador confiere significado a la onomástica. El apellido del cura Sota es un ejemplo obvio, pero también lo es el nombre de María Luz - que viene a "iluminar" con su belleza y generosidad la vida de los esclavos de La Tina.

(12) En la cit. carta a Maeztu, p. 8.

(13) Dentro de la vaga y esquemática caracterización de los per'sonajes menores resalta, sin embargo, la de las esclavas que rodean a María Luz. 
tinto y contrario a las normas aceptadas en sus respectivos "ambientes", y afirman la superioridad de la opción que ellos representan.

Las actitudes y palabras de los dos protagonistas son fuertemente críticas con respecto a los grupos a que pertenecen, sin duda, sin corresponder por ello a la visión propia de los desplazados. Por el contrario, cada cual en su contexto, María Luz y Matalaché ocupan lugares de privilegio. De esta suerte, el narrador obtiene las máximas ventajas posibles, dentro del esquema de novela que está empleando, para formalizar sus predicados. La crítica del universo social adquiere interioridad (son los amos quienes critican a los amos y son los esclavos quienes critican a los esclavos) y obtiene el prestigio de quienes la emiten. Naturalmente, este procedimiento no evita los discursos directos del narrador, cuyo contenido condenatorio es obvio, pero sí los incorpora dentro de un sistema de referencias que se solventa en el propio universo representado en la novela.

Es importante subrayar, pues, la soledad que caracteriza a María Luz y Matalaché. A excepción del intenso vínculo que une a ambos, uno y otro parecen condenados a quedarse en la epidermis de las relaciones humanas, rechazados más o menos claramente por sus semejantes y decididos, ellos mismos, a marcar las distancias correlativas a su excepcionalidad. María Luz apenas se relaciona superficialmente con su padre, sin lograr en ningún momento un nivel importante de comunicación, $\mathrm{y}$ con dos esclavas, en cuyo caso - $\mathrm{y}$ pese a la manifiesta cordialidad - se trata de relaciones intrínsecamente viciadas. El mulato José Manuel, por su parte, permanece aislado de su grupo: tiene plena conciencia de su singularidad y de las reacciones interiores que césta genera ("no' me gusta comer ni dormir en unión de los otros negros y siento algo que me aparta de ellos", p. 71) y sabe tambien, sin ufuda, que bos btros hegros esclavos sienten por él "antipatías y animosidad rayanas en el odio" (p. 69). En suma, según lo advierte el narrador, José Manuel “no conoció jamás (...) el amor de sus compañeros de desgracia" (p. 75). Curiosamente, la marginalidad social de Matalaché no le impide imaginarse como futuro guía de su pueblo (cree que llegará el momento en que su nombre se "oirá con respeto", p. 91) y tampoco obsta para que un viejo esclavo acepte esa posibilidad: "iquién sabe si vos serás nuestro salvadó!", le dice ño Parcemón (id).

Es claro que el rechazo de los dos protagonistas al "ambiente" de sus respectivos grupos se convierte en la novela en una requisitoria global contra la sociedad en su conjunto. Los temibles prejuicios que pervienten el orden social son explícitamente condenados por María Luz y José Manuel; más todavía, son destruidos a través de su propia experiencia. María Luz se libera del tabú sexual, rompe el orgulloso aislamiento de su clase, desobedece la norma básica del sistema esclavista: en suma, realiza existencialmente, en un acto que a este nivel ya es obviamente simbólico, los mandatos supremos de ese orden universal, primario, que la sociedad destruye. Su entrega a Ma- 
talaché afirma la igualdad de las razas, la perversión de la esclavitud por consiguiente, y proclama la irresistibilidad del "genio de la especie". Aunque tal vez con menos matices, puesto que el debate interior casi no existe en este caso, Matalaché repite la rebelión de su pareja: también él niega la jerarquía de las razas, condena la esclavitud (aunque jamás pase del límite de lo verbal) y obedece al imperio de su pasión por María Luz, pese a saber que con ello se juega la vida. En el universo de la novela, María Luz y José Manuel quedan instaurados, pues, como seres heroicos, claramente ejemplares, en combate con una sociedad maligna y poderosa.

\section{Las ambigüedades de la narración}

En el desenlace de Matalaché entran en juego algunos factores, discretamente subyacentes desde el comienzo del texto, que implican la recomposición del sistema significativo formalizado en el proceso novelesco. Así lo muestra la reflexión sobre el destino trágico de los dos protagonistas y la propia actitud de éstos luego de cumplido su reto frente a la sociedad. Ciertamente la horrible muerte de José Manuel y el oscuro destino de María Luz (¿muerta también?) (14) suponen el triunfo del universo social sobre las individualidades heroicas que quisieron, con su acción personal, destruirlo - y suponen asimismo, como es obvio, el fracaso práctico de los valores encarnados en la pareja. Naturalmente, no cabe olvidar la tradición literaria que hace de la muerte la confirmación de la intensidad de una pasión y de la heroicidad de sus protagonistas (basta pensar en Romeo y Julieta o en Calixto y Melibea, también actores, como José Manuel y María Luz, de un amor que encierra la negación del mundo social circundante); sin embargo, en Matalaché, el desenlace trágico no obedece íntegramente al mismo modelo. Queda transformado por la ambigua caracterización final de los protagonistas.

Luego de entregarse a José Manuel, María Luz comienza a sentirse "ganada (...) por el arrepentimiento". Cierto que luego se pregunta si "haber cedido a los impulsos del corazón" es "realmente una falta", y hasta encuentra alivio en pensar que, en definitiva, no ha hecho más que "darse en un acto de amor, como Jesús en la divina hora", pero -a la larga- su justificación personal tergiversa el sentido primario de su acto: en efecto, descubre "que lo que la llevara a entregarse no fue un simple anhelo de goce, sino un inconsciente sentimiento de piedad y sacrificio" (p. 155, subrayado nuestro), con lo que reviste "ideológicamente", y con elementos conceptuales propios del universo que niega (15), el sentido natural, primario, de su pasión.

(14) María Luz pide a su esclava que la mate. Cuando su padre se entera de sus relaciones con Matalaché le ordena a esa misma esclava: "Y si esa moza insiste en que la mates, imátala!" (p. 189). Is prácticamente lo último que se sabe de la protagonista.

(15) Fl entregarse a un hombre "por piedad" no sólo implica una nueva versión de la inferioridad de éste; implica también la transfor- 
No extraña, entonces, que el capítulo XV nos muestre a María Luz tan pronto confirmando su rebeldía (afirma que ni José Manuel "ni yo somos culpables de nada", p. 183) como lamentándose de su "perdida pureza": mi "reputación está por el suelo, enlodada", exclama María Luz poco antes de pedir a sus esclavas que la maten (p. 181). La contradicción alcanza niveles más agudos cuando la heroína, cuya entrega a Matalaché significa la igualdad entre los hombres, se niega a abortar porque "eso está bueno para las criadas y cierta clase de señoras" (p. 183), a la par que reivindica orgullosamente su condición señorial: ¿Que no sabes tú, Martina, quiénes somos los Ríos de Zúñiga?", pregunta María Luz a su esclava (p. 184).

El desarrollo de la caracterización de Matalaché es, asimismo, ambiguo. De hecho, la rebelión final de José Manuel frente a su amo, que incluye una condenación global de los "blancos" ("el esclavo es usted, don Juan, que se deja arrastrar por la soberbia, como el demonio. Así son todos ustedes los blancos"), se diluye en la contradicción que encierran las últimas palabras del esclavo. Ante su verdugo afirma con orgullo ser hijo de un noble español, don José Manuel Sojo (16), aun más encumbrado que los Ríos de Zúníiga, y que el hijo que deja en el vientre de María Luz habrá de ser "más generoso y noble" que don Juan Francisco puesto que en sus venas "tiene sangre de Sojo" (p. 194).

En el cuerpo del relato esta escena final corresponde con exactitud a algunos aspectos desarrollados anteriormente en relación a la excepcionalidad de Matalaché. Cabe recordar, entonces, que el esclavo José Manuel es presentado como un ser distinto a su grupo, y por esto marginal, y aclarar que tal diferencialidad deviene, para el narrador, del ancestro-blaneo del personaje. José Manuel aparece como "el negro meños gegrade des esclavos de La Tina" (p. 69) porque, en última instancia, es "negro por la piel, pero blanco por todo lo demás” (p. 70). La vigencia en Matalaché de los atributos de su encumbrado padre y de su madre esclava pueden ser claramente diferenciados: a aquél debe, por ejemplo, su apostura. Su nariz "recta, firme, dominadora, sensual" (fiel imagen de la de su padre) hace olvidar "ese horrible achatamiento de las [narices] de sus maternos progenitores, que vivieron eternamente exhibiéndolas como un signo de "drosería y bestialidad" (pp. 78-79). Pero se trata, sobre todo, de una "diferencia moral e intelectual que mientras al uno [a Matalaché] le iba permitiendo salir paulatinamente, por obra del propio esfuerzo, del bajo fondo en que yacía, a los otros [los esclavos sin "blanca intromisión”, p. 69] sumíalos en él cada día más” (p. 70). Dentro del contexto resulta indiscutible que esa fuerza moral tiene su origen primero en la herencia paterna.

mación del sentimiento originario, que obedecía a impulsos naturales igualitarios, en una actitud distinta que no se comprende más que a partir de la aceptación de los roles de ama y esclavo.

(16) Desde el capítulo VIII se insinúa la ascendencia noble de
José Manuel. 
Es claro que tanto la caracterización de Matalaché y el desarreglo del proceso psicológico de María Luz, tal como se advierte en el parágrafo anterior, cuanto el uso múltiple de un lenguaje extraído de la zoología para la mención de personajes negros, según se vio en su oportunidad, resquebrajan uno de los aspectos constitutivos de la explícita tesis de la novela (17). El principio aceptado de la diferencialidad de las razas se desliza peligrosamente hacia el prejuicio, escarnecido en el propio relato, de la jerarquía entre ellas. Se ha observado ya que ese proceso puede entenderse como una curiosa transposición del plano del universo representado (un mundo pervertido por poderosos prejuicios) al plano de la actitud narrativa básica, lo que necesariamente remite a un narrador indeciso e internamente contradictorio.

La explicación anterior no es suficiente. Existe también, en un nivel más profundo y de mayor capacidad esclarecedora, una contienda no resuelta entre la tesis (o mejor: las necesidades y condiciones estéticas de una novela concebida como novela de tesis) y el principio organizador de la verosimilitud. Tal como funciona Matalaché, la acción de este principio parece entenderse como la única garantía de que el relato sea aceptado por el lector. Desde esta perspectiva, la verosimilitud narrativa - su carácter de suceso cré́ble por el lectordeviene en instrumento de la tesis. La tesis sería inconvincente fuera del marco de la verosimilitud. Una y otra se presentan ante el narrador como solicitaciones simultáneas y -en este caso- conflictivas. En efecto, el amor entre el ama blanca y su esclavo negro, planteado inicialmente como suceso doblemente ejemplar en cuanto niega la vigencia de la jerarquía amos/esclavos y blancos/negros, parece ser reconocido por el narradoge enuel cdecursó delvpropio relato, como excesivamente insólito, inverosímil. De hecho, sólo a partir del capítulo VIII (que corresponde exactamente a la mitad de la novela y precede a la primera escena inequívocamente erótica entre María Luz y José Manuel) se insiste en la calidad excepcional del protagonista, antes mencionada sin mayor énfasis, y comienza a develarse su relación filial con el más encumbrado estrato del mundo de los blancos. El mulato de los primeros capítulos se convierte en el hijo de don José Manuel Sojo y en su carácter se suman, con velocidad creciente, rasgos cada vez más y más positivos. A la postre, María Luz se entrega no al "mulato veintiocheno, exúbero de belleza varonil, con vigor y flexibilidad de pantera" (p. 27), que es la primera imagen de Matalaché, sino al "negro menos negro de los esclavos de La Tina" ( 69), al descendiente de una estirpe por todos respetada.

Tensado entre la necesidad de postular una verdad y su axiología subyacente, por una parte, y la urgencia de armar su relato novelesco que el lector pueda aceptar, por otra, el narrador intenta equili-

(17) No son éstos los únicos indicios de la crisis del sentido de la tesis planteada en la novela, pero sí —-sin duda - los más significativos. 
brar su discurso entre uno y otro imperativo sin obtener siempre la deseada coherencia - lo que, incidentalmente, muestra uno de los conflictos claves de la narrativa realista hispanoamericana. Averiguar cómo y por qué el narrador obtuvo la imagen de su posible lector-aquél que se supone rechazaría el suceso inicialmente planteado- es tarea que escapa a los límites de este trabajo (18).

\section{Las varias formas de la esclavitud}

Por encima de la doble problemática planteada directamente en la novela, y comentada por nosotros hasta aquí, cabe distinguir otro nivel significativo no por tácito menos importante: es el que funciona a partir del juego metafórico que tiene como centro el signo "esclavitud". Su existencia se advierte muy claramente, en una primera instancia, a través de los discursos políticos de José Manuel. En ellos comienza a usarse extensivamente el término "esclavos" para designar a todos quienes, blancos o negros, poderosos o humildes, viven sojuzgados por el régimen colonial español. Refiriéndose a sus propósitos libertarios, Matalaché dice lo siguiente:

Lo que pienso hacer tendré que hacerlo con los otros, con los mismos que hoy nos oprimen y maltratan, mal que nos pese. $\mathrm{Y}$ es porque ellos son también esclavos como nosotros [esclavos de la metrópoli], pero tienen la cabeza más preparada para hacer mejor las cosas (p. 76, subrayado nuestro) (19).

A partir de aquí el lector descubre que la palabra "esclavo" y sus derivados aparecen constantemente en el texto y no sólo para re-

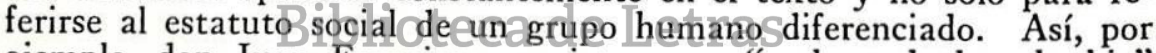
ejemplo, don Juan Francisco es visto como "esclavo de la soberbia" (p. 194) y su vilda como una linealidad sojuzgada a una "única ambición": el "enriquecimiento" (p. 63). Todos los habitantes de La Tina, "horros y esclavos, viejos y jóvenes", quedan rendidos ante la belleza de María Luz y terminan siendo "una masa de esclavos voluntarios, capaces de cometer por una sola caricia suya el más feroz de los crímenes" (p. 51). Naturalmente Matalaché no escapa a este destino: él también es esclavo de María Luz, doblemente esclavo si se quiere, por condición social y por pasión. En palabras del narrador:

(18) Es claro que el concepto de verosimilitud plantea la vigencia del lector en la creación de la obra. Lamentablemente es poco lo que la teoría literaria ofrece sobre este punto.

(19) Es conveniente advertir, aunque no corresponda directamente al sentido de este estudio, la importancia de los planteamientos de José Manuel sobre la emancipación del Perú, como una empresa común de "los blancos y los indios y los mestizos y todos los desesperados de esta tierra" (p. 90) contra la dominación española, y la sugestiva aunque parcial ambientación de la novela en los años previos a la Independencia. Las tensiones de la época quedan insinuadas en más de un episodio. 
La distancia infinita que a ambos separaba (...) engendró en su mente $(\ldots)$ otra esclavitud más fuerte todavía que la del hombre por el hombre; pero no odiosa ni humillante ni envilecedora como ésta, sino por el contrario, ennoblecedora y dulcí|sima (p. 67).

Dentro de este uso metafórico del término "esclavo", la figura de María Luz se percibe en un tránsito permanente de una a otra forma de esclavitud. Está esclavizada por el prejuicioso orden social ("no podía florecer por falta de luz y libertad", p. 95) y sometida a un tipo de vida que se le asocia al encarcelamiento ("y sola aquí, en esta especie de cárcel”, p. 120), donde en vez de "amor y ternura" sólo recibe "pan y comodidad”: "¡Como a sus esclavos!”, exclama María Luz refiriéndose al trato que recibe de los suyos (id.). Luego, bajo el imperio del sol piurano, María Luz se descubre sometida a la voluptuosidad:

No descansaba ni dormía: quimerizaba, tejía sobre el lecho, que besaba su gloriosa desnudez, una tela, dentro de la cual su pensamiento, por un extraño absurdo, se iba aprisionando a sí mismo, como el gusano en su capullo, y por más que trataba de romperla para recobrar su libertad, la red se espesaba y se espesaba (p. 50, subrayado nuestro).

No extraña, entonces, que María Luz se sienta "ya esclavizada también, como los seres infelices que la rodeaban" ( p. 51); ni extraña, tampoco, que su relación con José Manuel se perciba en términos semejantes: la mujer blanca confiesa que el mulato esclavo es su “dueño y señor" (p.121), el ţeñor de su corazón" (p. 176), porque se siente a sí misma oesclavizada por el despóțço poder del amor" (p. 144). Al terminar la novela, el narrador puede definir a María Luz como la mujer "más libre al parecer, pero en realidad la más esclava” (p. 185). La "más esclava”, en efecto, porque está sometida al rígido estatuto de su clase, y al poderoso sistema de prejuicios que ella impone, pero también, contradictoriamente, a la pasión y al amor; en otras palabras, a esa invencible fuerza del "genio de la especie".

Nuevamente se percibe aquí, claro que desde otro punto de mira, el doble orden (natural y social) que tiene que enfrentar el hombre en su existencia: el mandato de la naturaleza, que el hombre auténtico obedece, y el de la sociedad, que pervierte el sistema natural del mundo y envenena la vida del ser humano. Pero en uno $u$ otro caso, esclavo de la pasión y del amor ("esclavitud dulcísima"), o esclavo del convencionalismo y los prejuicios, el hombre aparece siempre sometido a fuerzas exteriores e incontrolables. Matalaché instaura un universo en el que la existencia humana, heroica o degradada, auténtica o alienada, feliz o trágica, se desplaza sin tregua y sin remedio de una a otra forma de esclavitud.

Lima, febrero de 1973. 